\title{
Application of remote sensing indices for mapping salt- affected areas by using field data methods
}

\author{
Mahdi Saghafi* \\ Department of Geography, Payame Noor University, Tehran, Iran
}

\section{ART ICLE INFO}

\section{Article history:}

Received 4 June 2017

Received in revised form

10 September 2017

Accepted 14 September 2017

\section{Keywords:}

Soil salinity

Mapping

Remote sensing indices

Electrical conductivity

Kaji Playa

\begin{abstract}
A B S T R A C T
Salinity is one of the oldest and most important environmental problems. Salinization is defined as presence of excessive salts on the top layer of the soil, resulting in deterioration of its chemical and physical properties. This is a form of land degradation turning into a major cause of low agricultural productivity in the South Khorasan province, Iran. The criteria defining saltaffected areas are based on electrical conductivity (EC) values. Kaji Playa is an endorheic basin that located in a distance of $190 \mathrm{~km}$ from the south of Birjand city in the South Khorasan province, Iran. The salt affected soils of Kaji Playa drainage basin cover approximately $39 \%$ of the study area and the EC values change from $4.2 \mathrm{dS} . \mathrm{m}-1$ to $245 \mathrm{dS} . \mathrm{m}-1$ (decisiemens per meter). Salinity Mapping is an expensive process, and a multi-scale strategy is essential to achieve a rapid and effective assessment of its extent and severity. Advantages of using remote sensing technology include saving time, wide coverage are faster than ground methods and facilitate long term monitoring. In this paper, we offered a project, which monitors soil salinity conditions in the study area using fieldwork, soil sample analysis, and a multi-temporal analysis of Landsat ETM+ data. The fieldwork was done to measure the soil salinity and gather ground truth for image classification. The alternative methodology of this study is based on the interpretation and calculation of salinity index from satellite data. The paper main aim included mapping and monitoring of salinity conditions for environmental management at basin level. According to the results, the soil salinity map produced by satellite index of NDSI (Normalized Difference Salinity Index) had an overall accuracy of $84 \%$ and Kappa index of $67 \%$, indicating an acceptable accuracy for this classification.
\end{abstract}

(C) 2017 The Authors. Published by IASE. This is an open access article under the CC BY-NC-ND license (http://creativecommons.org/licenses/by-nc-nd/4.0/).

\section{Introduction}

Soil salinization not only causes the destruction of resources and immense decline of agricultural productivity, but also threatens the biosphere and the ecological environment constitution. It often occurs in areas where drought occurs, the soil's evaporation is very intense, and the water table is high and contains high dissolubility salt. It takes place by some certain climates, terrain, and hydrogeology, all of which influence the water and salt movement. Today, soil salinization and secondary salinization are basic environmental issues that seriously influence the industrial and agricultural productions. Hence, the above factors by

\footnotetext{
* Corresponding Author.

Email Address: saghafi_mahdi@yahoo.com

https://doi.org/10.21833/ijaas.2017.010.025

2313-626X/C 2017 The Authors. Published by IASE.

This is an open access article under the CC BY-NC-ND license

(http://creativecommons.org/licenses/by-nc-nd/4.0/)
}

general purpose have a great sense of making reasonable measures to governance development.

In spite of general awareness of this problem and the related past experiences, salinization and water logging of irrigated lands are increasingly continuing. In some countries, land salinization may even threaten the national economy. This is a serious issue, particularly in Argentina, Egypt, India, Iraq, Pakistan, Syria, and Iran (Rhoades, 1990).

Although the statistics on salt affected areas varies according to Metternicht and Zinckc (1996), the estimates approximately indicate one billion hectares that is about 7\% of the earth's continental extent (Ghassemi et al., 1995), which is about 20 times more than France area.

In addition to the naturally salt affected areas, approximately 77 Mha have been salinized by human activities, $58 \%$ of which occur in irrigated areas. On average, $20 \%$ of all irrigated lands are affected by salts, while this rate increases to more than $30 \%$ in countries such as Egypt, Iran, and Argentina (Ghassemi et al., 1995). In the future, more 
dry lands will be put into agricultural production as a result of increasing population pressure. This will be mainly done with irrigation, and thus, would expand the salinization hazard.

It is widely acknowledged that dry land salinity is a major threat to the resource base of many rural areas across Iran. The farm and a wide cross section of the community are affected by salinity. In South Khorasn province of Iran, a land of approximately 2.5 Mha is salt-affected (GONRWM, 2005). South Khorasan province is located in NE of Kavir-e-Lut desert and the most part of the area is hydrologically drained. Therefore, these salt affected areas are mainly concentrated around the Kavir-e-Lut desert and their near lowlands and valley bottoms. It has been reported that a considerable extent of this area has been abandoned for cultivation due to the prevalence of salt affected soils around the Kavir-eLut. Recent reports also indicate that $23 \%$ of the South Khorasn farm lands are salt affected (GONRWM, 2005). These reports indicate the importance of the problem to meet the national food needs of the increasing population in the future, which is agreed to be met by directing the efforts of all concerned issues towards enhancing the management level of soils already under cultivation. While bringing new areas in action, some new areas of the dry land ecosystems are brought under cultivation (OWWDSA, 2007).

The approach to the problem of delineating saline soils using remote sensing data and GIS techniques has been proved in many recent studies to be the most efficient one. Johnston and Barson (1993) reviewed remote sensing applications in Australia. They found that the discrimination of saline areas was most successful strategy during the peak vegetation growth. Goossens and Van Ranst (1998) and Salman (2000) analyzed the beginning, middle and end of the growing season in the western Nile Delta and concluded that single image may be suitable for detecting severely salinized soils, but more gradations can be determined by using temporal images.

Boonstra et al. (2002) reviewed the studies conducted by different researchers on direct observations on bare soils and indirectly on vegetation coverage. Seghal et al. (1988) applied Landsat MSS data for mapping salt affected soils in the frame of the reconnaissance soil map of India. Dwivedi (1992) used Landsat MSS and TM data for more detailed mapping and monitoring of the salt affected soils in the Indo-Gangetic alluvial plain, India. Goossens et al. (1999) indicated the development of GIS and remote sensing for monitoring and prediction of soil salinity in the Nile Delta, Egypt. Goossens and Van Ranst (1996) have shown the possibility of detecting different soil types, especially gypsiferous soils, by the choice of thermal band.

Three major objectives of this study are as follows: a) Assessment and mapping of the distribution of salinity problems in different parts of the study area, which might be useful for effective management of the salinity problem, and thereby its prevention in the future.

b) Applying different salt indices to detect salt affected areas by satellite data.

c) Identifying the best method for salt-affected soil mapping.

\section{Study area specifications}

In this paper, the study area is an endorheic basin that retains water and allows no outflow. Bottom of the basin is occupied seasonally by the body of water and is called Kaji Playa. Kaji Playa Lake is located at South Khorasan province in east of Iran with a total area of $2487 \mathrm{~km} 2$. The study area is located between latitude $31.9014 \mathrm{~N}$ to $32.263 \mathrm{~N}$ and longitude $59.634 \mathrm{E}$ to $60.205 \mathrm{E}$, in a distance of $190 \mathrm{~km}$ from the south of Birjand city near Nehbandan town (Fig. 1).

Both arid and semiarid climates occur in the area. In the lower elevations of valleys and basin floors, the annual precipitation is about $10.8 \mathrm{~cm}$. Short term records of precipitation at several places in the Kaji drainage basin suggest that the climate above an elevation of about $1200 \mathrm{~m}$ is semiarid, with precipitation ranging from approximately 12.6 to $16.2 \mathrm{~cm}$. Annual evaporation is approximately 13 times of the annual precipitation. The size and shape of Kaji Playa change dramatically over time in response to the climate changes.

Morphologically, the crest of the mountain forms the highest elevation boundary of the drainage basin and elongates from northwest to southeast. The topography of the drainage basin area in the north and south boundary is extreme, and is characterized by small knob like hills in the southeast and northwest area of the basin. This hummocky topography expands across the southeastern drainage basin boundary (Fig. 1).

Local mountain bedrock is the source of a variety of residual, colluvial, and alluvial parent materials. The major bedrock types are rhyolite, andesite, monzonite, and marine carbonate rocks that are mainly composed of limestone and dolostone with interbedded cherts and clastic rocks comprising from shale, siltstone, and sandstone (Darvishzadeh, 2000).

The central basin is a flat plain with floors bounded by piedmont slopes, consisting of alluvial fans and coalescent fan piedmonts descending from the mountains.

The landforms of the Kaji Playa basin are predominantly related to fluvial and aeolian, formed since the late Pleistocene. Fluvial landforms are generally the youngest features of the landscape. Soils are usually less developed in the study area due to alluvial processes activity and the periodic disturbance caused by inundation, erosion, and deposition. 


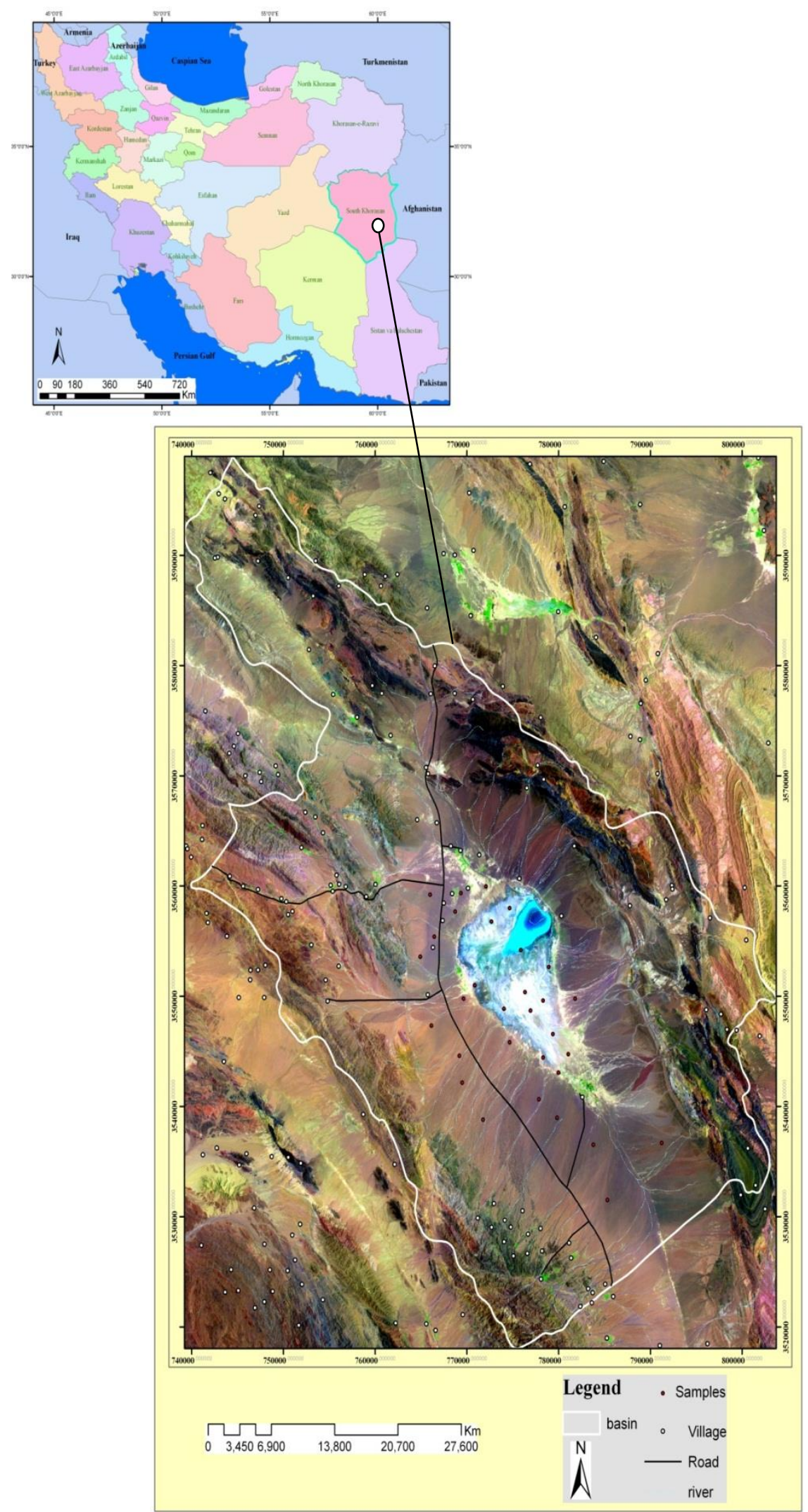

Fig. 1: Study area shown in false color composite (RGB 742) of Landsat7 ETM+, 2009, and locations of soil sampling sites.

Ground water surface elevations within the drainage basin range from about $50 \mathrm{~m}$ in the slopes of mountain to less than $1 \mathrm{~m}$ near the Playa Lake. Soils and vegetation also reflect a change from arid to semiarid conditions. Soils around the Playa Lake have lighter and thinner horizons and deeper zones of clay and carbonate accumulation.

\subsection{Kaji Playa lake}

The salt flat covers the center of the Kaji Playa basin as an efflorescent crust. It occupies more than $21 \%$ of the Playa surface and determines the most characteristic feature of the Playa Lake. It occurs in the lowest area of the Kaji endorheic drainage basin (Fig. 1). 
The development of saline soils in the Kaji Playa is related to the saturated groundwater flows. As a result, these flows between particles of rocks and soils dissolve and transport the soluble salts. The groundwater emerges at the soil surface in a discharge area. When water evaporates, salt is left behind on the soil surface. Over time, the salts are accumulated in the discharge area, and eventually the salt concentration increases so that the plant growth is restricted. The principal salt found in the salt flat of the study area was halite, but calcium chloride hexahydrate existed also as minor values. The Halite was in massive form.

In the Kaji Playa, salt crystallization begins at the brine surface as small plates. In this process, the individual floating crystals are cemented together where in contact with each other form rafts. When the surface tension is disturbed, the crystals fall to the bottom, forming an accumulation of individual halite crystals, and then, the broken rafts falls on the brine pool floor. The thickness of salt crust ranges from a few centimeters in south to 10 centimeters in north. They are usually clear and white in color. The surface layer comprises some sand sized grains. The volume percentage of these sediments is located in different places.

According to the classification made by Kwiatkowski et al. (1995), the Kaji Playa Lake has a regional system recharge area at the water division place of a basin, while the discharge area lies at the bottom of the basin. Regional systems may even extend over several kilometers.

In order to form the saline soils, the water table needs to come close enough to the soil surface. This allows the capillary action to raise the groundwater to the soil surface. In this case, the water is required to be within the depth of $2 \mathrm{~m}$ of the soil surface. The critical depth (the depth beyond which the water cannot wick to the soil surface) varies with soil texture (Henry et al., 1987). In the Playa brine, the level slightly fluctuates during dry and wet seasons and it does not fall more than $20 \mathrm{~cm}$ below the salt surface, which is normally moist. Below this surface, the voids in salt and sediment layers are filled with halite or saturated brines.

The sedimentology facies found in the saline pans through cores and pits consisted of layers of crystalline salt and detrital siliciclastic (mud and sand). They were in the form of salt, black mud, loose sand, sandy mud and brown clay facies.

\section{Material and methods}

The fieldwork of the studied area was carried out by soil sample analysis and multi-temporal analysis of Landsat ETM+ data. The fieldwork included measuring the soil salinity and gathering the ground truth for image classification.

Field investigations and sample collections were carried out in the bare soil of the plain unit. Geographical positions of the sampling points were recorded using a Garmin E-Trex GPS. In this study, 31 soil samples were analyzed and the EC values of the soil samples were tested in $\mathrm{dS} / \mathrm{m}$ at the topsoil $(0-50 \mathrm{~cm})$ using pocket EC meters. A general guideline for the degree of soil salinity is given in Table 1.

In order to find the relationship between the soil salinity and DN values for the total pixels of the bare soil, the soil salinity data was interpolated. To interpolate the available soil salinity data, the data basis of 31 EC values of soil samples were interpolated by GIS software. Finally, three different classes were recognized according to the degree of salinity (Table 1).

Table 1: Criteria for soil salinity classification

\begin{tabular}{cc}
\hline degree of salinity & Salinity EC $(\mathrm{dS} . \mathrm{m}-1)$ \\
\hline slight & $4-8$ \\
moderate & $8-25$ \\
severe & $>25$
\end{tabular}

The alternative methodology of this study is based on the interpretation and calculation of salinity indices from satellite data. For this purpose, we used Landsat ETM+ image that represented the dry season. Table 2 shows the date of the used image and its specifications.

Table 2: Specifications of the used image

\begin{tabular}{cccc}
\hline Resolution & Date & Path & Satellite \\
\hline 28.5 & $2009-10-13$ & $158 / 03800$ & Landsat 7 ETM+ \\
\hline
\end{tabular}

Digital processing of the satellite data was carried out using ERDAS IMAGINE software.

First, the satellite images were corrected. Climatically, the acquisition time of the RS data is important for the identification of soil salinity. Therefore, after checking the uniformity of the atmosphere over the scenes, a simple haze compensation procedure (Richards and Richards, 1999) was applied to minimize the influence of path radiance effects (Lillesand et al., 2014). Then, a subscene of $3580 \mathrm{~km} 2$ encompassing the study area was extracted and registered. Co-registration of all image bands is necessary in order to perform the salinity analysis. To establish co-registration of all image bands, the control points from the Iranian Army Topographic maps at 1:25000 scales were used as a reference for the band 1 of 2009 image and the other image bands were registered to this sub-scene. Approximately, 35 ground-control points were selected from topographic-map features with clarity on the image. An independent set of points was selected and used to assess the accuracy of the coregistration. The root mean square error (RMS) of verification points is a better estimator of registration accuracy than the RMS of the control points used for development of the rectification model (Dwyer, 1995). The maximum verification error from co-registration of all images was $65 \mathrm{~m}$ in the X-and $89 \mathrm{~m}$ in the Y-direction. All of the images were re-sampled to form a pixel size of $25 \mathrm{~m}$.

In order to enhance the saline zones, two indices were proposed by using the satellite images: (a) Salinity Index (SI); (b) Normalized Difference Salinity Index (NDSI). SI is the ratio of red band to 
near infrared (NIR) band (Eq. 1), while NDSI is the ratio of the difference of the red and NIR bands divided by the summation of the two (Eq. 2). SI and NDSI are computed as follows:

$$
\begin{aligned}
& S I=\left(\frac{\text { Band } 3}{\text { Band } 4}\right) \\
& N D S I=\frac{(\text { band } 3-\text { Band } 4)}{(\text { Band } 3+\text { Bamd } 4)}
\end{aligned}
$$

\section{Results from field work analysis}

An attempt was made to predict the salinity level at different locations from the interpolation of 31 points of observation. The locations were spatially distributed evenly all over the study area to measure EC's (Fig. 1). The employed procedure to predict the salinity level at un-sampled locations was an interpolation using Arc GIS Spatial Analyst Extension (Fig. 2A). Summary statistics of samples for EC calculation are shown in the Table 3. The study area is categorized into three salinity levels according to the ground truth:

1) Slight saline,

2) Moderate saline, and

3) Severe saline.

The salt-affected soils are encountered at the lower slopes of the terrain and occupied 39\% of the total study area (Table 4). They are mostly encountered in the broad plain and valley physiographic unit and in adjacent upland areas.

\subsection{Results from indices analysis}

According to the results of NDSI and SI remote sensing indices, it was found that an area with high raster value or high reflectance was delineated as an area affected by salinity problem. Once the areas having high reflectance value were identified, the level of the salinity was determined based on their reflectance value. In the NDSI image, the salt-affected areas are depicted in gray color and can roughly be differentiated from those of non-salt-affected areas, water logged and vegetation. Since the salinity problem dynamics varies with time in nature and the used image was captured in 2009 year, the ground truth only gave slight indications of the presence of salt-affected area.

The result of salinity level in NDSI and SI indices is shown in Figs. 2B and $2 \mathrm{C}$ respectively. The extent of the area in percentage is given in the Table 4.

\section{Conclusion}

Field data analysis for EC vs NDSI and SI using regression analysis represented the determination coefficient of $71.1 \%$ and $59.6 \%$, respectively. The spatial distribution of salt affected land derived from field data were checked by comparison with salt affected area derived from NDSI, indicating that the same area extent was in highly saline class, while other classes showed less significant relation (Table 4).

Table 3: Summary results of EC analysis for Kaji Playa drainage basin.

\begin{tabular}{cc}
\hline Item & $\mathrm{EC}(\mathrm{dS} / \mathrm{m})$ \\
\hline Minimum & 4.2 \\
Maximum & 245 \\
Average & 3.671128 \\
Standard deviation & 8.423 \\
\hline
\end{tabular}

Table 4: Salinity classification in the study area resulted from NDSI and SI indices.

\begin{tabular}{cccc}
\hline \multirow{2}{*}{ Class name } & \multicolumn{3}{c}{ Area in \% } \\
\cline { 2 - 4 } & NDSI & SI & Field data \\
\hline water logging & 0.18 & 0.15 & 0.27 \\
none saline & 0.38 & 0.42 & 0.34 \\
slightly saline & 0.21 & 0.12 & 0.19 \\
Moderately Saline & 0.11 & 0.17 & 0.07 \\
Highly Saline & 0.12 & 0.14 & 0.13 \\
\hline
\end{tabular}

The application of the NDSI index was found to be a good indication of soil salinity in the study area. Therefore, the application of this salinity index was a good indicator of the existence of soil salinity, and thus, it could be used as one of the main inputs for soil management. It may influence the decisions on reclamations of soil salinity. The results derived from SI index would not be considered so acceptable. However, they presented a clear idea about the reflectance properties of salt affected area as well as other features.

The current standard to report the results of the classification accuracy assessment focuses on the error or confusion matrix, which summarizes the comparison of map class labels with reference data labels. Some easily computed summary statistics for the error matrix include overall map accuracy, proportion correction by classes (user and producer accuracy), and errors of omission and commission. Additional summary statistics usually include a Kappa (Khat) coefficient that adjusts the correction of the overall proportion for the possibility of chance agreement (Congalton and Green, 2008). As a result, the soil salinity classification map produced by the NDSI index approach had an overall accuracy of $84 \%$ and Kappa index of $67 \%$. On the other hand, soil salinity classification map produced by the SI index approach had an overall accuracy of $64 \%$ and Kappa index of $51 \%$. Finally, according to the results of the accuracy assessment analysis, the use of NDSI index for mapping soil salinity in the study area was more suitable. Also, many other researchers have used satellite imagery for mapping and monitoring soil salinity. For example, Elnaggar and Noller (2009) used Landsat TM imagery integrated with decision tree analysis to map soil salinity in central Malheur County. They found that there was a significant relationship between EC values and reflectance in Landsat bands 1, 2, 3 and 4. Katawatin and Kotrapat (2005), Mehrjardi et al. (2008) and Yu et al. (2010) have investigated the utility and effectiveness of $\mathrm{ETM}+$ data for soil salinity mapping and monitoring. Katawatin and Kotrapat (2005) investigated the use of Landsat-7 ETM+ with different combinations of 
three sources of ancillary data for soil salinity mapping.

The purpose of classifying and mapping salinity was to identify various types and extents to quantify the issue and move toward the recommended management practices. The maps provided an excellent extension tool to local agents and let farmers know the extent of salinity issues beyond their property. Data analyses allow policy makers to
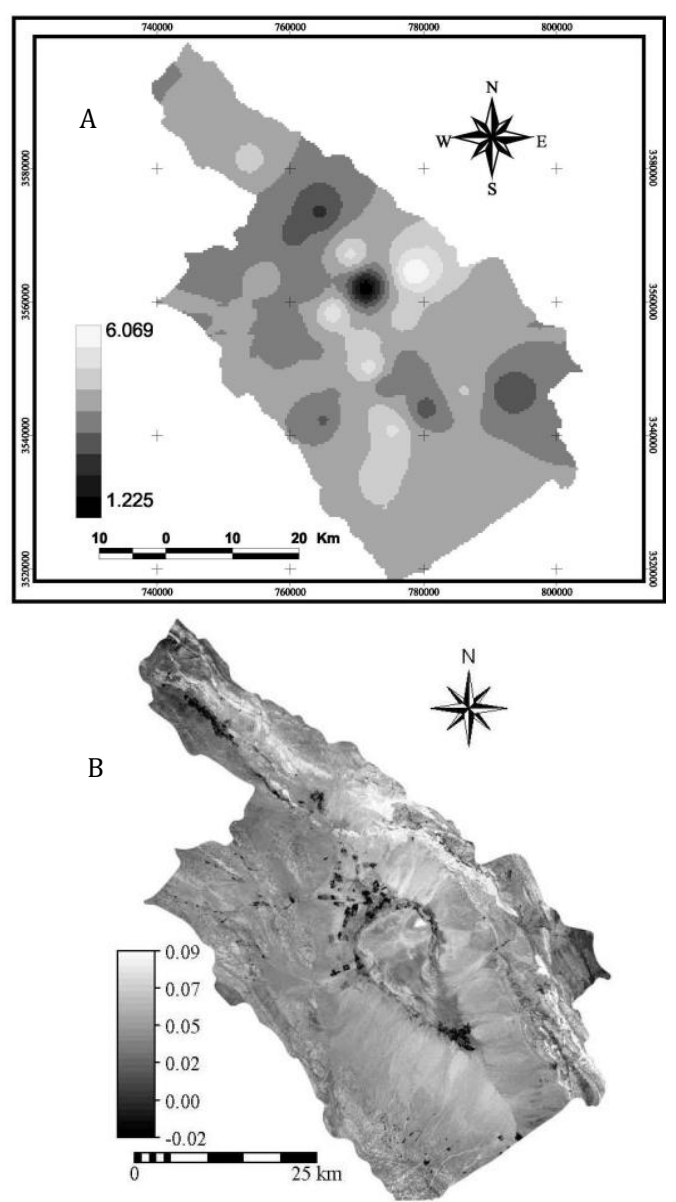

design and target programs specific to the extent and the nature of the problem. In this study, from the output maps resulted from field data salinity analysis and classification of NDSI index, one can easily see that those areas categorized as severe saline are located near to Kaji Playa Lake, North and central part of the drainage basin and flat slope areas of the estate.

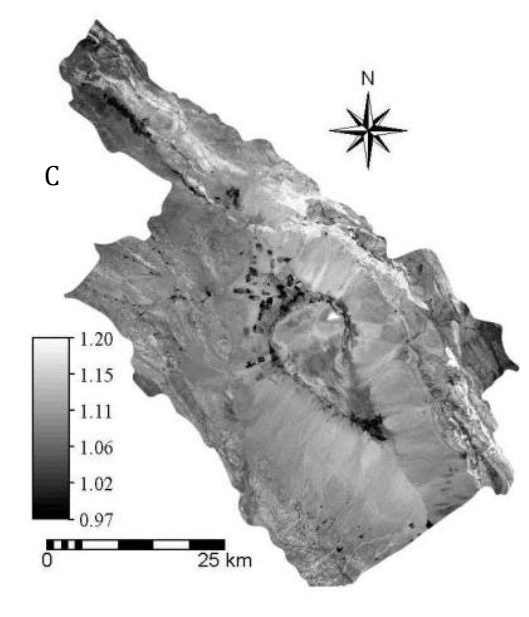

Fig. 2: Soil salinity maps: (A) Salt affect area resulted from field data EC interpolation; (B) NDSI index; (C) SI index

\section{References}

Boonstra J, Ritzema HP, Wolters W, Oosterbaan RJ, and van Lieshout AM (2002). A methodology for identification of waterlogging and soil salinity conditions using remote sensing. CSSRI, Kamal and Alterra-ILRI, Wageningen, Netherlands.

Congalton RG and Green K (2008). Assessing the accuracy of remotely sensed data: principles and practices. CRC Press, Boca Raton, USA.

Darvishzadeh A (2000). Geology of Iran. Amir Kabir University, Tehran, Iran.

Dwivedi R (1992). Monitoring and the study of the effects of image scale on delineation of salt-affected soils in the Indo-Gangetic plains. International Journal of Remote Sensing, 13(8): 15271536.

Dwyer JL (1995). Mapping tidewater glacier dynamics in East Greenland using Landsat data. Journal of Glaciology, 41(139): 584-595.

Elnaggar AA and Noller JS (2009). Application of remote-sensing data and decision-tree analysis to mapping salt-affected soils over large areas. Remote Sensing, 2(1): 151-165.
Ghassemi F, Jakeman AJ, and Nix HA (1995). Salinisation of land and water resources: Human causes, extent, management and case studies. CABI, Wallingford, UK.

GONRWM (2005). Soil report of South Khorasan Province. General Office of Natural Resources and Watershed Management in Provincial South Khorasan, South Khorasan, Iran.

Goossens R and Van Ranst E (1996). The use of remote sensing and GIS to detect gypsiferous soils in the Ismailia Province (Egypt). In the International Conference on Soils with Gypsum. Lleida, Spain: 15-21. Available online at: http://hdl.handle.net/1854/LU-261012

Goossens R and Van Ranst E (1998). The use of remote sensing to map gypsiferous soils in the Ismailia Province (Egypt). Geoderma, 87(1-2): 47-56.

Goossens R, Alavi Panah SK, De Dapper M, and Kissyar 0 (1999). The use of thermal band of Landsat TM for the study of soil salinity in Iran (Ardakan area) and Egypt (Ismailia Province). In the International Conference on Geoinformatics for Natural Resource Assessment, Monitoring and Management, Indian Institute of Remote Sensing, Dehradun, India: 454-459.

Henry L, Harron B, and Flaten D (1987). Nature and management of salt-affected land in Saskatchewan. Saskatchewan Agriculture, Soils and Crops Branch, Watrous, SK, Canada. 
Johnston RM and Barson MM (1993). Remote sensing of Australian wetlands: An evaluation of Landsat TM data for inventory and classification. Marine and Freshwater Research, 44(2): 235-252.

Katawatin R and Kotrapat W (2005). Use of LANDSAT-7 ETM+ with ancillary data for soil salinity mapping in northeast Thailand. In the Third International Conference on Experimental Mechanics and Third Conference of the Asian Committee on Experimental Mechanics (SPIE 5852): 708-716. http://doi.org/10.1117/12.621889

Kwiatkowski J, Marciak LC, Wentz D, and King CR (1995). Salinity mapping for resource management within the county of Wheatland, Alberta, Conservation and Development Branch, Alberta Agriculture. Food and Rural Development, Edmonton, Alberta, Canada.

Lillesand T, Kiefer RW, and Chipman J (2014). Remote sensing and image interpretation. John Wiley and Sons, Hoboken, USA.

Mehrjardi TR, Mahmoodi S, Taze M, and Sahebjalal E (2008). Accuracy assessment of soil salinity map in Yazd-Ardakan Plain: Central Iran Based on Landsat ETM+ Imagery. American-Eurasian Journal of Agriculture and Environmental Sciences, 3(5): 708-712.

Metternicht GI and Zinckc JA (1996). Spatial discrimination of salt-alkalinity classes for mapping salt affected topsoils in the semi aired valleys of Cochamamba (Bolivia). ITC-Journal, 2: 125-135.

OWWDSA (2007). Soil survey and land evaluation report. Fentale irrigation based development project, unpublished feasibility study. Oromia Water Works Design and Supervision Authority, Addis Ababa, Ethiopia.

Rhoades JD (1990). Soil salinity-causes and controls. In: Goudie AS (ed.), Techniques for desert reclamation: 109-134. John Wiley and Sons Ltd, Chichester, West Sussex, UK.

Richards JA and Richards JA (1999). Remote sensing digital image analysis. Springer, Berlin, Germany.

Salman A (2000). Using the state-of-the-art remote sensing and GIS for monitoring water logging and Salinity. International Water-Management Institute, Lahore, Pakistan.

Seghal JL, Saxena RK, and Verma KS (1988). Soil resource inventory of India using image interpretation techniques, remote sensing is a tool for soil scientists. In the $5^{\text {th }}$ Symposium of the Working Group Remote Sensing ISSS, Budapest, Hungary: 17-31.

Yu R, Liu T, Xu Y, Zhu C, Zhang Q, Qu Z, and Li C (2010). Analysis of salinization dynamics by remote sensing in Hetao Irrigation District of North China. Agricultural Water Management, 97(12): 1952-1960. 